\title{
Association of Homocysteine Levels With Blood Lead Levels and Micronutrients in the US General Population
}

\author{
Yu-Mi Lee', Mi-Kyung Lee'², Sang-Geun Bae', Seon-Hwa Lee', Sun-Young Kim³, Duk-Hee Lee' \\ 'Department of Preventive Medicine, Kyungpook National University School of Medicine, Daegu; ${ }^{2}$ Department of Family Medicine, Kyungpook \\ National University Hospital, Daegu; ${ }^{3}$ Department of Public Health, Kyungpook National University Graduate School, Daegu, Korea
}

Objectives: Even though several epidemiological studies have observed positive associations between blood lead levels and homocysteine, no study has examined whether this association differs by the levels of micronutrients, such as folate, vitamin B6, and vitamin B12, which are involved in the metabolism of homocysteine. In this study, we examined the interactions between micronutrients and blood lead on homocysteine levels.

Methods: This study was performed with 4089 adults aged $\geq 20$ years old in the US general population using the National Health and Nutrition Examination Survey 2003-2004.

Results: There were significant or marginally significant interactions between micronutrients and blood lead levels on mean homocysteine levels. Positive associations between blood lead and homocysteine were clearly observed among subjects with low levels of folate or low vitamin B6 ( $p$-trend $<0.01$, respectively). However, in the case of vitamin B12, there was a stronger positive association between blood lead and homocysteine among subjects with high levels of vitamin B12, compared to those with low levels of vitamin B12. In fact, the levels of homocysteine were already high among subjects low in vitamin B12, irrespective of blood lead levels. When we used hyperhomocysteinemia (homocysteine $>15 \mu \mathrm{mol} / \mathrm{L}$ ) as the outcome, there were similar patterns of interaction, though $p$ values for each interaction failed to reach statistical significance.

Conclusions: In the current study, the association between blood lead and homocysteine differed based on the levels of folate, vitamin B6, or vitamin B12 present in the blood. It may be important to keep sufficient levels of these micronutrients to prevent the possible harmful effects of lead exposure on homocysteine levels.

Key words: Homocysteine, Lead, Folic acid, Vitamin B6, Vitamin B12

\section{INTRODUCTION}

Elevated homocysteine is known to be an independent risk

Received: June 30, 2012 Accepted: October 10, 2012

Corresponding author: Duk-Hee Lee, MD, PhD

680 Gukchaebosang-ro, Jung-gu, Daegu 700-842, Korea

Tel: +82-53-420-4866, Fax: +82-53-425-2447

E-mail: lee_dh@knu.ac.kr

This is an Open Access article distributed under the terms of the Creative Commons Attribution Non-Commercial License (http://creativecommons.org/licenses/by$\mathrm{nc} / 3.0 / /$ which permits unrestricted non-commercial use, distribution, and reproduction in any medium, provided the original work is properly cited. factor for cardiovascular disease [1,2]. Since widespread arteriosclerosis in patients with homocystinuria, which is caused by deficiencies of enzymes involved in homocysteine metabolism, was first reported in 1969 [3], many clinical and epidemiological researches have shown that an elevated homocysteine level is a potent independent risk factor for arteriosclerosis in the general population [1]. For example, a meta-analysis of observational studies indicated that increased homocysteine levels were a modest independent predictor of coronary heart disease and cerebrovascular disease risk in healthy populations [2]. Although controversy exists regarding a causal relationship, increased homocysteine levels have also been linked with im- 
paired cognitive function $[4,5]$.

High levels of homocysteine are linked to genetic mutations (e.g., 677C $\rightarrow$ T mutation in 5,10-methylenetetrahydrofolate reductase [MTHFR]), physiological factors (e.g., increasing age, male gender, and postmenopausal state), lifestyle factors (e.g., smoking), deficiency of micronutrients (e.g., folate, vitamin B6, and vitamin B12), and some clinical conditions (e.g., renal failure, hypothyroidism, and late stage of diabetes) $[6,7]$.

On the other hand, several recent studies have reported a positive relationship between blood lead and homocysteine levels in the general population or lead-exposed workers, suggesting that heavy metals like lead can disturb the metabolism of homocysteine [8-11]. Lead, in particular, can disturb essential enzymes in the metabolism of homocysteine like cystathionine $\beta$-synthase or MTHFR [12-14]. Notably, micronutrients such as folate, vitamin B6, and vitamin B12 are also involved in the pathways of homocysteine metabolism. Therefore, there is a possibility of interaction between blood lead levels and these micronutrients on the levels of homocysteine.

However, to the best of our knowledge, there has been no study exploring this hypothesis. Thus, we examined whether the association between blood lead and homocysteine differs depending on the levels of micronutrients like folate, vitamin $\mathrm{B} 6$, and vitamin B12 in a general population.

\section{METHODS}

\section{Study Population}

The National Health and Nutrition Examination Survey (NHANES), carried out annually by the Centers for Disease Control and Prevention, is a complex, multi-stage probability research designed to measure the health and nutritional status of the non-institutionalized US general population [15]. In this study, data from NHANES 2003-2004 were used. Among the 5041 participants aged 20 years or older in NHANES 20032004,4089 subjects with valid measured values of plasma homocysteine, whole blood lead, vitamin B6, serum folate, and vitamin B12 levels were included in this study.

\section{Measures}

The details of the NHANES protocol and all testing procedures are available elsewhere [15]. Demographic, socioeconomic, and health related characteristics were collected from detailed interview using the standardized questionnaire in participant's homes. Physiological measurements and labora- tory tests were conducted by highly trained medical personnel in specially designed and equipped mobile centers.

Venous blood samples were collected and shipped weekly at $-20^{\circ} \mathrm{C}$. Total homocysteine levels in plasma was determined by the Abbott Homocysteine assay on the Abbott AxSym analyzer, a fully automated fluorescence polarization immunoassay obtained from Abbott Diagnostics (Abbott Laboratories, Abbott Park, IL, USA). Whole blood lead concentration was measured using inductively coupled plasma mass spectrometry, a multi-element analytical technique [16]. Both serum folate and vitamin B12 levels were determined by using the BioRad Laboratories "Quantaphase II Folate/Vitamin B12" radioassay kit (Bio-Rad Laboratories, Hercules, CA, USA). Plasma pyridoxal 5'- phosphate (PLP), the biologically active form of vitamin B6, was measured using the Enzymatic B6 Assay (A/C Diagnostics, San Diego, CA, USA).

\section{Statistical Analysis}

Blood lead levels were categorized into quartiles (Q1 to Q4) by cutoff points at the 25 th, 50th, and 75 th percentile values. Because the range of the highest quartile level (Q4) was too wide, it was sub-divided into four additional categories (Q4-1 to Q4-4), making seven categories of blood lead levels, in total.

First, we evaluated the associations between blood lead levels and homocysteine using a generalized linear model. Also, using logistic regression analysis, we calculated adjusted odds ratios (ORs) for hyperhomocysteinemia (level of plasma homocysteine $>15 \mu \mathrm{mol} / \mathrm{L}$ ) according to the categories of blood lead levels. Possible confounders were age (years, continuous), sex, race/ethnicity (non-Hispanic white, non-Hispanic black, Hispanic, and other), and poverty income ratio (PIR; an index calculated by family income divided by the poverty threshold, specific to family size, continuous). Briefly, a PIR of less than 1 indicates a family income below the poverty threshold; a PIR of more than 1 indicates a family income one or more times the poverty threshold, body mass index (BMl; $\mathrm{kg} / \mathrm{m}^{2}$, continuous), smoking status (never, former, or current), alcohol consumption (none or current), and physical activity (inactive, moderate, or vigorous). Just as previous studies have done $[8,11]$, we further considered as confounders serum folate (ng/ $\mathrm{mL}$, continuous), vitamin B12 (pg/mL, continuous), and plasma vitamin B6 (nmol/L, continuous).

Second, we calculated the associations of blood lead levels with continuous homocysteine or dichotomous hyperhomocysteinemia stratified by median levels of serum folate, vita- 
$\min B 6$, and vitamin $B 12$ to determine whether the associations differed depending on micronutrient levels. All statistical analyses were conducted with SAS version 9.2 (SAS Inc., Cary, NC, USA) and SUDAAN version 9.0 (RTI International, Research Triangle Park, NC, USA). Instead of using sample weights, estimates of main results were calculated accounting for stratification and clustering [17], adjusting for age, sex, race/ethnicity, and PIR; this adjustment is considered a good compromise between efficiency and bias $[17,18]$. The results from SAS and from SUDAAN were very similar, so we present the results based on SAS. A $p$-value of less than 0.05 was considered statistically significant.

\section{RESULTS}

\section{General Characteristics of the Study Subjects Ac-} cording to the Categories of Blood Lead Levels

The sample of 4089 subjects had a mean age of $50.4 \pm 19.3$ years old. The mean BMI was $28.4 \pm 6.2 \mathrm{~kg} / \mathrm{m}^{2}$ and mean PIR was 2.6 \pm 1.6 . Mean values of serum folate, vitamin B6, and vi- tamin B12 were $14.2 \pm 15.1 \mathrm{ng} / \mathrm{mL}, 67.4 \pm 82.4 \mathrm{nmol} / \mathrm{L}$, and $555.2 \pm 846.6 \mathrm{pg} / \mathrm{mL}$, respectively. The study subjects were $48.7 \%$ male, $53.8 \%$ non-Hispanic white, $18.5 \%$ current smokers, $71.4 \%$ current drinkers, and $41.4 \%$ physically inactive people. Subjects with high blood lead levels tended to be older, male, less obese, non-Hispanic white, current smokers, current drinkers, and have a lower PIR and be more physically inactive ( $p$-trend $<0.001$ for all these variables) compared with those with low blood lead levels (Table 1).

\section{Associations of Blood Lead Levels With Homo-} cysteine Levels or Hyperhomocysteinemia

Homocysteine levels showed a positive trend with blood lead levels. In the unadjusted analysis, mean homocysteine levels according to the categories of blood lead levels were 7.5, 9.1, 10.0, 10.1, 11.0, 11.2, and $12.2 \mu \mathrm{mol} / \mathrm{L}$, respectively ( $p$-trend $<0.001$ ) (Table 2). This linear relationship between homocysteine and blood lead remained statistically significant after adjusting for covariates including age, sex, race/ethnicity, PIR, BMI, smoking, alcohol consumption, and physical activity.

Table 1. General characteristics of the all study subjects according to the categories of blood lead

\begin{tabular}{|c|c|c|c|c|c|c|c|c|c|}
\hline \multirow{3}{*}{ Characteristics } & \multirow{3}{*}{$\begin{array}{c}\text { Total } \\
(\mathrm{n}=\mathbf{4 0 8 9})\end{array}$} & \multicolumn{7}{|c|}{ Quartiles of blood lead levels } & \multirow{3}{*}{$p$-trend } \\
\hline & & \multirow{2}{*}{$\begin{array}{c}01 \\
(\mathrm{n}=971)\end{array}$} & \multirow{2}{*}{$\begin{array}{c}02 \\
(n=1100)\end{array}$} & \multirow{2}{*}{$\begin{array}{c}03 \\
(n=1001)\end{array}$} & \multicolumn{4}{|c|}{$\mathbf{0 4}$} & \\
\hline & & & & & $\begin{array}{c}04-1 \\
(n=252)\end{array}$ & $\begin{array}{c}04-2 \\
(n=242)\end{array}$ & $\begin{array}{c}04-3 \\
(n=270)\end{array}$ & $\begin{array}{c}04-4 \\
(n=253)\end{array}$ & \\
\hline \multicolumn{10}{|l|}{ Mean \pm standard deviation } \\
\hline Blood lead $(\mu \mathrm{g} / \mathrm{dL})$ & $\begin{array}{l}2.1 \pm 1.8 \\
(0.2-33.0)\end{array}$ & $\begin{array}{c}0.8 \pm 0.2 \\
(0.2-1.0)\end{array}$ & $\begin{array}{c}1.3 \pm 0.2 \\
(1.1-1.6)\end{array}$ & $\begin{array}{c}2.1 \pm 0.3 \\
(1.7-2.5)\end{array}$ & $\begin{array}{c}2.7 \pm 0.1 \\
(2.6-2.9)\end{array}$ & $\begin{array}{c}3.2 \pm 0.1 \\
(3.0-3.4)\end{array}$ & $\begin{array}{c}3.9 \pm 0.3 \\
(3.5-4.5)\end{array}$ & $\begin{array}{l}7.2 \pm 3.7 \\
(4.6-33.0)\end{array}$ & \\
\hline Age (y) & $50.4 \pm 19.3$ & $38.7 \pm 16.9$ & $48.1 \pm 18.4$ & $55.3 \pm 17.7$ & $56.4 \pm 17.3$ & $61.3 \pm 17.0$ & $59.5 \pm 18.0$ & $59.7 \pm 18.5$ & $<0.001$ \\
\hline Body mass index $\left(\mathrm{kg} / \mathrm{m}^{2}\right)$ & $28.4 \pm 6.2$ & $29.1 \pm 7.6$ & $28.5 \pm 5.9$ & $28.7 \pm 5.8$ & $27.8 \pm 5.6$ & $27.5 \pm 4.6$ & $27.2 \pm 5.2$ & $27.4 \pm 5.3$ & $<0.001$ \\
\hline Poverty income ratio & $2.6 \pm 1.6$ & $2.7 \pm 1.6$ & $2.7 \pm 1.6$ & $2.6 \pm 1.6$ & $2.5 \pm 1.6$ & $2.4 \pm 1.5$ & $2.1 \pm 1.5$ & $2.0 \pm 1.4$ & $<0.001$ \\
\hline Serum folate $(\mathrm{ng} / \mathrm{mL})$ & $14.2 \pm 15.1$ & $14.5 \pm 10.5$ & $14.5 \pm 23.2$ & $14.2 \pm 12.4$ & $14.2 \pm 8.9$ & $14.1 \pm 8.0$ & $13.4 \pm 8.6$ & $12.2 \pm 9.3$ & 0.03 \\
\hline Vitamin B6 (nmol/L) & $67.4 \pm 82.4$ & $60.7 \pm 80.5$ & $69.3 \pm 78.2$ & $75.3 \pm 95.2$ & $61.1 \pm 53.3$ & $73.0 \pm 91.8$ & $62.8 \pm 68.7$ & $59.5 \pm 78.5$ & 0.98 \\
\hline Vitamin B12 (pg/mL) & $555.2 \pm 846.6$ & $511.9 \pm 429.8$ & $522.4 \pm 281.7$ & $569.4 \pm 688.3$ & $721.4 \pm 2244.2$ & $517.9 \pm 293.1$ & $636.8 \pm 1605.9$ & $591.7 \pm 887.5$ & 0.009 \\
\hline \multicolumn{10}{|c|}{ 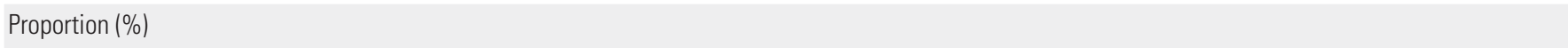 } \\
\hline Male & 48.7 & 24.8 & 46.6 & 55.0 & 62.7 & 66.5 & 65.6 & 75.5 & $<0.001$ \\
\hline Non-Hispanic white & 53.8 & 60.8 & 54.5 & 51.5 & 52.8 & 53.3 & 49.6 & 39.5 & $<0.001$ \\
\hline Current smokers & 18.5 & 10.9 & 16.9 & 19.0 & 25.4 & 23.1 & 26.7 & 33.2 & $<0.001$ \\
\hline Current drinkers & 71.4 & 67.0 & 67.3 & 73.8 & 79.4 & 74.8 & 73.7 & 82.2 & $<0.001$ \\
\hline Physically inactive & 41.4 & 31.9 & 38.0 & 43.1 & 48.4 & 47.5 & 52.2 & 60.9 & $<0.001$ \\
\hline Folate deficiency ${ }^{1}$ & 0.4 & 0.1 & 0.5 & 0.3 & 1.6 & 0.4 & 0.4 & 1.2 & 0.03 \\
\hline Vitamin B6 deficiency² & 22.0 & 30.5 & 20.0 & 17.6 & 17.9 & 19.4 & 20.4 & 23.7 & $<0.001$ \\
\hline Vitamin B12 deficiency ${ }^{3}$ & 2.2 & 2.1 & 2.2 & 2.2 & 0.8 & 1.7 & 3.7 & 3.6 & 0.17 \\
\hline
\end{tabular}

Q1, first quartile; 02 , second quartile; 03 , third quartile; 04 , fourth quartile.

${ }^{1}$ Serum folate levels $<3 \mathrm{ng} / \mathrm{mL}$

${ }^{2}$ Plasma vitamin B6 (pyridoxal 5'-phosphate) levels $<20 \mathrm{nmol} / \mathrm{L}$.

${ }^{3}$ Serum vitamin B12 levels $<200 \mathrm{pg} / \mathrm{mL}$. 
Table 2. Mean homocysteine level' (mean \pm standard error, $\mu \mathrm{mol} / \mathrm{L}$ ) and odds ratios' (95\% confidence intervals) for hyperhomocysteinemia depending on the categories of blood lead level among study subjects

\begin{tabular}{|c|c|c|c|c|c|c|c|c|}
\hline & \multicolumn{7}{|c|}{ Quartiles of blood lead levels } & \multirow{3}{*}{$p$-trend } \\
\hline & \multirow{2}{*}{01} & \multirow{2}{*}{02} & \multirow{2}{*}{03} & \multicolumn{4}{|c|}{04} & \\
\hline & & & & 04-1 & 04-2 & 04-3 & 04-4 & \\
\hline \multicolumn{9}{|c|}{ Outcome: homocysteine ( $\mu \mathrm{mol} / \mathrm{L})$} \\
\hline Model 1 & $7.5 \pm 0.2$ & $9.1 \pm 0.1$ & $10.0 \pm 0.1$ & $10.1 \pm 0.3$ & $11.0 \pm 0.3$ & $11.2 \pm 0.3$ & $12.2 \pm 0.3$ & $<0.001$ \\
\hline Model 2 & $9.0 \pm 0.2$ & $9.5 \pm 0.2$ & $9.6 \pm 0.2$ & $9.5 \pm 0.3$ & $10.0 \pm 0.3$ & $10.3 \pm 0.3$ & $11.1 \pm 0.3$ & $<0.001$ \\
\hline Model 3 & $9.2 \pm 0.2$ & $9.7 \pm 0.2$ & $9.8 \pm 0.2$ & $9.6 \pm 0.3$ & $10.1 \pm 0.3$ & $10.3 \pm 0.3$ & $11.2 \pm 0.3$ & $<0.001$ \\
\hline Model 4 & $9.2 \pm 0.2$ & $9.7 \pm 0.2$ & $9.8 \pm 0.2$ & $9.6 \pm 0.3$ & $10.0 \pm 0.3$ & $10.3 \pm 0.3$ & $11.1 \pm 0.3$ & $<0.001$ \\
\hline \multicolumn{9}{|c|}{ Outcome: hyperhomocysteinemia (>15 $\mu \mathrm{mol} / \mathrm{L}$ ) } \\
\hline Cases/no. & 21/971 & 49/1100 & 68/1001 & $22 / 252$ & 20/242 & $42 / 270$ & $50 / 253$ & \\
\hline Model 1 & 1.0 (reference) & $2.1(1.3,3.5)$ & $3.3(2.0,5.4)$ & $4.3(2.3,8.0)$ & $4.1(2.2,7.7)$ & $8.3(4.8,14.4)$ & $11.1(6.6,19.0)$ & $<0.001$ \\
\hline Model 2 & 1.0 (reference) & $1.3(0.7,2.2)$ & $1.4(0.8,2.4)$ & $1.8(0.9,3.4)$ & $1.3(0.7,2.6)$ & $2.9(1.6,5.3)$ & $3.9(2.2,7.0)$ & $<0.001$ \\
\hline Model 3 & 1.0 (reference) & $1.2(0.7,2.1)$ & $1.3(0.8,2.3)$ & $1.6(0.8,3.1)$ & $1.3(0.6,2.5)$ & $2.7(1.5,4.9)$ & $3.3(1.8,6.0)$ & $<0.001$ \\
\hline Model 4 & 1.0 (reference) & $1.2(0.7,2.0)$ & $1.3(0.8,2.3)$ & $1.6(0.8,3.1)$ & $1.2(0.6,2.4)$ & $2.6(1.4,4.8)$ & $3.2(1.7,5.9)$ & $<0.001$ \\
\hline
\end{tabular}

Q1, first quartile; 02 , second quartile; 03 , third quartile; 04 , fourth quartile.

'Model 1: unadjusted; Model 2: adjusted for age, sex, race/ethnicity, and poverty income ratio; Model 3: further adjusted for body mass index, smoking, alcohol, and physical activity; Model 4: further adjusted for serum folate, vitamin B6, and vitamin B12.

However, the magnitude of the increase was smaller than the unadjusted analysis: 9.2, 9.7, 9.8, 9.6, 10.1, 10.3, and $11.2 \mu \mathrm{mol} / \mathrm{L}$, respectively ( $p$-trend $<0.001$ ). Further adjustment for serum folate, vitamin B6, and vitamin B12 did not change the results.

When we used the dichotomous outcome of hyperhomocysteinemia, the unadjusted ORs were 1.0, 2.1, 3.3, 4.3, 4.1, 8.3, and 11.1 across the categories of blood lead levels ( $p$-trend $<0.001$ ) (Table 2). After all covariates were adjusted, the ORs for hyperhomocysteinemia were 1.0, 1.2, 1.3, 1.6, 1.2, 2.6, and 3.2 ( $p$-trend $<0.001$ ).

These patterns were similarly observed among subjects without chronic diseases, specifically coronary artery disease, cerebral vascular disease, hypertension, diabetes, cancers, thyroid disease, and kidney disease, which could influence homocysteine levels (data not shown).

\section{Stratified Analyses by the Level of Serum Folate,} Vitamin B6, or Vitamin B12

When study subjects were stratified according to the median value of serum folate, vitamin B6, or vitamin B12, the positive association between blood lead levels and homocysteine levels were more clearly observed among subjects with lower folate ( $p$-trend $<0.001$ ) or lower vitamin B6 ( $p$-trend $<0.001$ ) (Table 3). There was a stronger positive association between blood lead and homocysteine among subjects with high vitamin B12 than those with low vitamin B12 ( $p$-trend $<0.001$ ); and subjects with low vitamin B12 already had high levels of homocysteine, irrespective of blood lead levels. A $p$-value for interaction was statistically significant or marginally significant for all three micronutrients.

There were similar patterns in general when we used hyperhomocysteinemia as the outcome, though $p$-values for interactions failed to reach statistical significance (Table 3). Namely, clear and statistically significant increasing trends were observed only among subjects with lower folate ( $p$-trend 0.003 ) or lower vitamin B6 ( $p$-trend $<0.001$ ). In the case of vitamin $B 12$, the positive association tended to be observed among subjects with both lower and higher vitamin B12 ( $p$-trend 0.012 and 0.005 , respectively). We also presented the adjusted ORs, using subjects with blood lead levels in the 1st quartile and micronutrients less than the median value as the reference group, to give a comprehensive view on the combination effect of lead and each micronutrient (Figure 1).

\section{DISCUSSION}

Our current study showed a linear association between blood lead and homocysteine among the US general population even though $95.2 \%$ of study subjects had blood lead levels less than $5 \mu \mathrm{g} / \mathrm{dL}$. In addition, as we hypothesized, the association between lead and homocysteine differed depending on serum folate, vitamin B6, and vitamin B12 levels.

The association between blood lead and homocysteine is consistent with the findings of several previous studies [8-11]. 
Table 3. Adjusted' homocysteine level (mean \pm standard error, $\mu \mathrm{mol} / \mathrm{L}$ ) and ORs ( $95 \% \mathrm{Cls}$ ) for hyperhomocysteinemia depending on the categories of blood lead level after stratifying by the median² value of folate, vitamin B6, or vitamin B12

\begin{tabular}{|c|c|c|c|c|c|c|c|}
\hline & & \multicolumn{6}{|c|}{ Quartiles of blood lead levels } \\
\hline & & 01 & 02 & 03 & 04 & $p$-trend & $p$-interaction \\
\hline \multicolumn{8}{|l|}{ Folate } \\
\hline$<$ Median & & $9.6 \pm 0.3$ & $10.0 \pm 0.2$ & $10.2 \pm 0.2$ & $10.9 \pm 0.2$ & $<0.001$ & 0.06 \\
\hline$\geq$ Median & & $9.0 \pm 0.3$ & $9.3 \pm 0.2$ & $9.1 \pm 0.2$ & $9.3 \pm 0.2$ & 0.515 & \\
\hline \multicolumn{8}{|l|}{ Vitamin B6 } \\
\hline <Median & & $9.3 \pm 0.3$ & $9.9 \pm 0.3$ & $10.2 \pm 0.3$ & $10.7 \pm 0.3$ & $<0.001$ & 0.002 \\
\hline$\geq$ Median & & $9.2 \pm 0.2$ & $9.5 \pm 0.2$ & $9.5 \pm 0.2$ & $9.8 \pm 0.2$ & 0.087 & \\
\hline \multicolumn{8}{|l|}{ Vitamin B12 } \\
\hline <Median & & $10.4 \pm 0.3$ & $10.9 \pm 0.3$ & $10.9 \pm 0.3$ & $11.2 \pm 0.3$ & 0.081 & 0.01 \\
\hline$\geq$ Median & & $8.0 \pm 0.2$ & $8.5 \pm 0.1$ & $8.7 \pm 0.1$ & $9.3 \pm 0.1$ & $<0.001$ & \\
\hline \multicolumn{8}{|c|}{ ORs for hyperhomocysteinemia } \\
\hline \multicolumn{8}{|c|}{ Folate } \\
\hline$<$ Median & $\begin{array}{l}\text { Cases/no. } \\
\text { OR (95\% CI) }\end{array}$ & $\begin{array}{l}11 / 440 \\
1.0 \text { (reference) }\end{array}$ & $\begin{array}{c}29 / 557 \\
1.2(0.6,2.5)\end{array}$ & $\begin{array}{c}45 / 503 \\
1.5(0.7,3.2)\end{array}$ & $\begin{array}{l}88 / 552 \\
2.3(1.1,4.7)\end{array}$ & 0.003 & 0.74 \\
\hline$\geq$ Median & $\begin{array}{l}\text { Cases/no. } \\
\text { OR (95\% CI) }\end{array}$ & $\begin{array}{l}10 / 531 \\
1.0 \text { (reference) }\end{array}$ & $\begin{array}{l}20 / 543 \\
1.1(0.5,2.4)\end{array}$ & $\begin{array}{c}23 / 498 \\
0.8(0.4,1.8)\end{array}$ & $\begin{array}{l}46 / 465 \\
1.5(0.7,3.2)\end{array}$ & 0.237 & \\
\hline \multicolumn{8}{|l|}{ Vitamin B6 } \\
\hline$<$ Median & $\begin{array}{l}\text { Cases/no. } \\
\text { OR (95\% CI) }\end{array}$ & $\begin{array}{l}7 / 552 \\
1.0 \text { (reference) }\end{array}$ & $\begin{array}{l}23 / 505 \\
1.9(0.8,4.5)\end{array}$ & $\begin{array}{c}43 / 467 \\
2.7(1.2,6.4)\end{array}$ & $\begin{array}{l}82 / 520 \\
3.8(1.6,9.0)\end{array}$ & $<0.001$ & 0.06 \\
\hline$\geq$ Median & $\begin{array}{l}\text { Cases/no. } \\
\text { OR (95\% CI) }\end{array}$ & $\begin{array}{l}14 / 419 \\
1.0 \text { (reference) }\end{array}$ & $\begin{array}{c}26 / 595 \\
0.9(0.5,1.8)\end{array}$ & $\begin{array}{c}25 / 534 \\
0.7(0.3,1.3)\end{array}$ & $\begin{array}{l}52 / 497 \\
1.3(0.7,2.5)\end{array}$ & 0.305 & \\
\hline \multicolumn{8}{|l|}{ Vitamin B12 } \\
\hline$<$ Median & $\begin{array}{l}\text { Cases/no. } \\
\text { OR (95\% CI) }\end{array}$ & $\begin{array}{l}15 / 509 \\
1.0 \text { (reference) }\end{array}$ & $\begin{array}{c}39 / 541 \\
1.3(0.7,2.5)\end{array}$ & $\begin{array}{l}50 / 481 \\
1.3(0.7,2.5)\end{array}$ & $\begin{array}{c}98 / 513 \\
2.0(1.1,3.9)\end{array}$ & 0.012 & 0.64 \\
\hline$\geq$ Median & $\begin{array}{l}\text { Cases/no. } \\
\text { OR (95\% CI) }\end{array}$ & $\begin{array}{c}6 / 462 \\
1.0 \text { (reference) }\end{array}$ & $\begin{array}{c}10 / 559 \\
1.0(0.3,2.8)\end{array}$ & $\begin{array}{c}18 / 520 \\
1.4(0.5,3.7)\end{array}$ & $\begin{array}{c}36 / 504 \\
2.7(1.0,7.1)\end{array}$ & 0.005 & \\
\hline
\end{tabular}

Q1, first quartile; 02 , second quartile; 03 , third quartile; 04 , fourth quartile; $\mathrm{OR}$, odds ratio; $\mathrm{Cl}$, confidence interval.

${ }^{1}$ Adjusted for age, sex, race/ethnicity, poverty income ratio, body mass index, smoking, alcohol, and physical activity.

${ }^{2}$ Median values of serum folate, vitamin B6, and vitamin B12 are $11.6 \mathrm{ng} / \mathrm{mL}, 45.6 \mathrm{nmol} / \mathrm{L}$, and $465.0 \mathrm{pg} / \mathrm{mL}$, respectively.
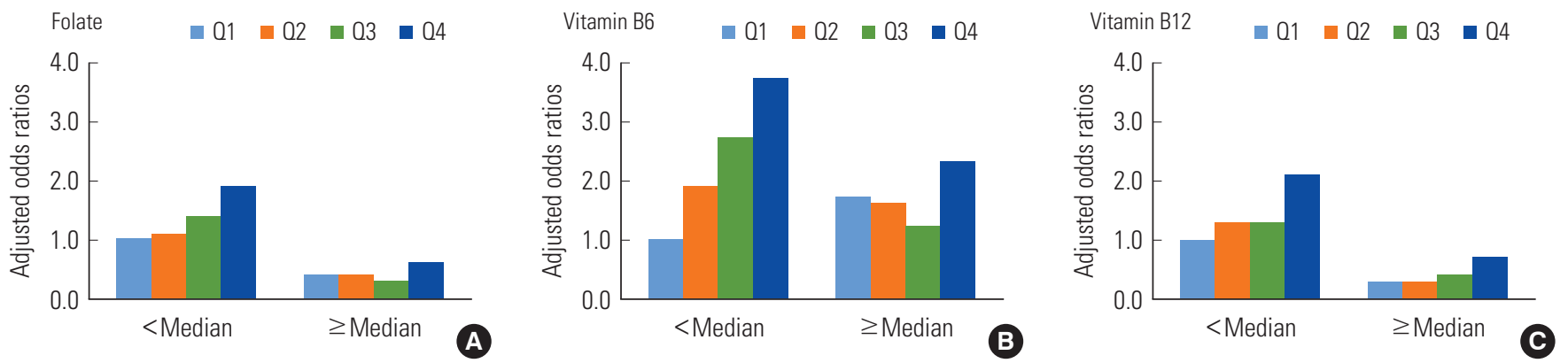

Figure 1. Interactions between blood lead levels and micronutrients (A, folate; B, vitamin B6; and C, vitamin B12) on hyperhomocysteinemia. Odds ratios were adjusted for age, sex, race/ethnicity, poverty income ratio, BMI, smoking, alcohol, and physical activity. Subjects with the lowest quartile of blood lead and each micronutrient (A, folate; B, vitamin B6; and C, vitamin B12) less than the median were used as a reference.

Q1: first quartile; Q2: second quartile; Q3: third quartile; Q4: fourth quartile.

For example, in the Baltimore Memory Study, a populationbased study of adults aged 50 to 70 years old, homocysteine levels increased $0.35 \mu \mathrm{mol} / \mathrm{L}$ per every $1.0 \mu \mathrm{g} / \mathrm{dL}$ increase in blood lead [9]. In a study of Vietnamese factory workers occu- 
pationally exposed to lead, an elevation of $1.0 \mu \mathrm{g} / \mathrm{dL}$ in blood lead was associated with an elevation of $0.05 \mu \mathrm{mol} / \mathrm{L}$ in homocysteine on the logarithmic scale [10]. Two other general population studies, one of US adults aged 20 to 59 years old who participated in the NHANES and the other of Pakistani adults aged 18 to 60 years old, also showed an increase of homocysteine as blood lead levels increased [8,11]. Based on our findings and those of other studies, it could be suggested that blood lead levels could be another predictor of hyperhomocysteinemia.

Importantly, we observed statistically significant interactions between blood lead and the micronutrients folate, vitamin B6, and vitamin B12, which are involved in transmethylation or transsulfuration metabolism on homocysteine levels. The positive association between blood lead and homocysteine was mainly observed when the levels of folate or vitamin B6 were low while there was no clear association among subjects with high levels of folate or vitamin B6. On the other hand, unlike folate or vitamin B6, in the case of vitamin B12, the positive association was observed only among subjects with high vitamin B12 levels. In fact, homocysteine levels were already substantially high among subjects with low vitamin B12 levels irrespective of blood lead levels. If homocysteine levels increase above certain levels, additional synergic effects of blood lead levels may be negligible.

Meanwhile, although the $p$-values of interactions between blood lead levels and micronutrients on the blood concentrations of homocystein were marginally significant or significant, those in a logistic regression using a dichotomous variable for hyperhomocysteinemia as an outcome, failed to reach statistical significance. As the continuous homocysteine levels tested additive interactions while the dichotomous hyperhomocysteinemia tested multiplicative interactions, more significant results in the additive interactions can be expected. Even though the multiplicative interactions failed to reach statistical significances, it is notable that the patterns of interactions were similarly observed in both models.

Homocysteine is a sulfur-containing amino acid derived from the metabolism of methionine, and can be metabolized by one of two pathways: 1) transsulfuration to cysteine, and 2) remethylation to methionine [19]. In the transsulfuration pathway, homocysteine is transformed to cystathionine by the enzyme cystathionine $\beta$-synthase with vitamin $B 6$, which is a PLP-dependent heme-containing enzyme $[19,20]$. Because lead toxicity inhibits heme and hemoglobin synthesis [21], this could be one mechanism that explains the observed association between blood lead and homocysteine.

In addition, in the remethylation pathway, homocysteine can be remethylated to methionine through the enzyme methionine synthase with vitamin B12, folate, and MTHFR [19]. At the same time, it has been suggested that the variant enzyme MTHFR might cause lead to bind more to active sites, which may result in the impairment of enzyme function [14]. On the other hand, the heavy metals, including lead, have high electron-sharing affinities for the free sulfhydryl group of proteins $[21,22]$. As homocysteine itself contains a sulfhydryl group, blood lead may inhibit the metabolism of homocysteine by this pathway. Taken together, there is a possibility that lead might directly inactivate the enzymes involved in methionine metabolism, or might adhere competitively to the active site for homocysteine, or homocysteine itself. Lead can also biologically interact with folate, vitamin B6, and vitamin B12.

Current study has some limitations. First, in this cross-sectional study we cannot determine the causality between blood lead and homocysteine, despite the biological plausibility discussed above. Second, we could not consider gene mutation, which is already known to be associated with the level of homocysteine (e.g., point mutation of enzyme MTHFR $677 C \rightarrow T$ ). It is difficult to imagine that blood lead levels would be different depending on the mutation of enzyme MTHFR. Therefore, gene mutation may not act as a strong confounder in this study. However, further studies on the effect of genetic polymorphisms of enzymes involved in homocysteine metabolism would be helpful to understand the current findings.

Regardless of these limitations, the current study has several strengths. First, this study employed the strict sampling design, large sample size, and controlled quality of study measurements used in NHANES. Second, to best of our knowledge, this is the first study to investigate the interaction between the level of blood lead and the micronutrients involved in the metabolism of homocysteine in estimating the level of serum homocysteine.

In conclusion, we found that mean homocysteine levels and the risk of hyperhomocysteinemia increased with blood lead levels. Importantly, these relationships differed by the level of the micronutrients involved in the metabolism of homocysteine. It may be important to maintain sufficient levels of these micronutrients to prevent possible lead exposure from harming the metabolism of homocysteine. 


\section{ACKNOWLEDGEMENTS}

This research was supported by the Basic Science Research Program through the National Research Foundation of Korea funded by the Ministry of Education, Science and Technology (2010-0011905).

\section{CONFLICT OF INTEREST}

The authors have no conflicts of interest with the material presented in this paper.

\section{REFERENCES}

1. McCully KS. Hyperhomocysteinemia and arteriosclerosis: historical perspectives. Clin Chem Lab Med 2005;43(10):980-986.

2. Homocysteine Studies Collaboration. Homocysteine and risk of ischemic heart disease and stroke: a meta-analysis. JAMA 2002;288(16):2015-2022.

3. McCully KS. Vascular pathology of homocysteinemia: implications for the pathogenesis of arteriosclerosis. Am J Pathol 1969; 56(1):111-128.

4. Vogel T, Dali-Youcef N, Kaltenbach G, Andrès E. Homocysteine, vitamin B12, folate and cognitive functions: a systematic and critical review of the literature. Int J Clin Pract 2009;63(7): 1061-1067.

5. Ho RC, Cheung MW, Fu E, Win HH, Zaw MH, Ng A, et al. Is high homocysteine level a risk factor for cognitive decline in elderly? A systematic review, meta-analysis, and meta-regression. Am J Geriatr Psychiatry 2011;19(7):607-617.

6. Refsum H, Smith AD, Ueland PM, Nexo E, Clarke R, McPartlin J, et al. Facts and recommendations about total homocysteine determinations: an expert opinion. Clin Chem 2004;50(1):3-32.

7. Ganji V, Kafai MR; Third National Health and Nutrition Examination Survey. Demographic, health, lifestyle, and blood vitamin determinants of serum total homocysteine concentrations in the third National Health and Nutrition Examination Survey, 1988-1994. Am J Clin Nutr 2003;77(4):826-833.

8. Yakub M, lqbal MP. Association of blood lead (Pb) and plasma homocysteine: a cross sectional survey in Karachi, Pakistan. PLoS One 2010;5(7):e11706.

9. Schafer JH, Glass TA, Bressler J, Todd AC, Schwartz BS. Blood lead is a predictor of homocysteine levels in a populationbased study of older adults. Environ Health Perspect 2005;
113(1):31-35.

10. Chia SE, Ali SM, Lee BL, Lim GH, Jin S, Dong NV, et al. Association of blood lead and homocysteine levels among lead exposed subjects in Vietnam and Singapore. Occup Environ Med 2007;64(10):688-693.

11. Krieg EF Jr, Butler MA. Blood lead, serum homocysteine, and neurobehavioral test performance in the third National Health and Nutrition Examination Survey. Neurotoxicology 2009; 30(2):281-289.

12. Bar-Or D, Rael LT, Thomas GW, Kraus JP. Inhibitory effect of copper on cystathionine beta-synthase activity: protective effect of an analog of the human albumin N-terminus. Protein Pept Lett 2005;12(3):271-273.

13. Waly M, Olteanu H, Banerjee R, Choi SW, Mason JB, Parker BS, et al. Activation of methionine synthase by insulin-like growth factor- 1 and dopamine: a target for neurodevelopmental toxins and thimerosal. Mol Psychiatry 2004;9(4):358-370.

14. Yakub M, Moti N, Parveen S, Chaudhry B, Azam I, Iqbal MP. Polymorphisms in MTHFR, MS and CBS genes and homocysteine levels in a Pakistani population. PLoS One 2012;7(3): e33222.

15. Centers for Disease Control and Prevention. National Health and Nutrition Examination Survey: NHANES 2003-2004 [cited 2012 May 7]. Available from: http://www.cdc.gov/nchs/ nhanes/nhanes2003-2004/nhanes03_04.htm.

16. Date AR, Gray AL. Applications of Inductively Coupled Plasma Mass Spectrometry. New York: Chapman and Hall; 1989, p. 1-38.

17. Korn EL, Graubard Bl. Epidemiologic studies utilizing surveys: accounting for the sampling design. Am J Public Health 1991; 81(9):1166-1173.

18. Graubard BI, Korn EL. Analyzing health surveys for cancer-related objectives. J Natl Cancer Inst 1999;91(12):1005-1016.

19. Zhou J, Austin RC. Contributions of hyperhomocysteinemia to atherosclerosis: causal relationship and potential mechanisms. Biofactors 2009;35(2):120-129.

20. Meier M, Janosik M, Kery V, Kraus JP, Burkhard P. Structure of human cystathionine beta-synthase: a unique pyridoxal 5'-phosphate-dependent heme protein. EMBO J 2001;20(15): 3910-3916.

21. Flora SJ, Mittal M, Mehta A. Heavy metal induced oxidative stress \& its possible reversal by chelation therapy. Indian J Med Res 2008;128(4):501-523.

22. Quig D. Cysteine metabolism and metal toxicity. Altern Med Rev 1998;3(4):262-270. 